\title{
Altered expression of IncRNA NCK1-AS1 distinguished patients with prostate cancer from those with benign prostatic hyperplasia
}

\author{
ZHIHUI GUAN ${ }^{1,2^{*}}$, YUWEI SONG ${ }^{3 *}$, JINGUO MA $^{4}$, FENG LI $^{1}$, XIAOJUN ZHAO ${ }^{1}$, \\ GUODONG LIANG ${ }^{5}$, HAIQUAN AN ${ }^{2}$ and JINXIAN PU ${ }^{1}$ \\ ${ }^{1}$ Department of Urology, The First Affiliated Hospital of Soochow University, Suzhou, Jiangsu 215006; Departments of \\ ${ }^{2}$ Urology, ${ }^{3}$ Pediatrics, ${ }^{4}$ Oncology and ${ }^{5}$ Pathology, Hulunbuir People's Hospital, Hulunbuir, Inner Mongolia 021008, P.R. China
}

Received March 27, 2019; Accepted August 20, 2019

DOI: $10.3892 / 01.2019 .11039$

\begin{abstract}
Long non-coding (lnc)RNA NCK1 antisense RNA 1 (NCK1-AS1) has been characterized as an oncogene in cervical cancer, while its role in prostate cancer (PC) remains unknown. It was revealed in the present study that plasma NCK1-AS1 was upregulated in patients with PC when compared with patients with benign prostatic hyperplasia (BPH) and healthy controls. Upregulation of NCK1-AS1 distinguished patients with PC from patients with $\mathrm{BPH}$ and healthy controls. Overexpression of NCK1-AS1 led to significantly upregulated transforming growth factor (TGF)- $\beta 1$, while TGF- $\beta 1$ overexpression failed to significantly affect NCK1-AS1 in PC cells. NCK1-AS1 overexpression led to promoted migration and invasion. TGF- $\beta$ inhibitor played an opposite role and attenuated the effects of NCK1-AS1 overexpression. Therefore, NCK1-AS1 may upregulate TGF- $\beta 1$ to promote PC.
\end{abstract}

\section{Introduction}

Prostate cancer (PC) is the most common type of malignancy and the second major cause of cancer-associated mortalities in males worldwide in 2018 (1). Due to its aggressive nature, PC can develop rapidly and invade surrounding tissues, or even develop into metastatic PC, leading to poor prognosis (2). The progression of PC is closely correlated with dysregulated androgen receptor, and ablation of androgen is the primary treatment method for PC $(3,4)$. However, castration-resistance will inevitably develop after 18-24 months of androgen

Correspondence to: Dr Jinxian Pu, Department of Urology, The First Affiliated Hospital of Soochow University, 188 Shizi Street, Suzhou, Jiangsu 215006, P.R. China

E-mail: rqpwwxkb13269247@126.com

${ }^{*}$ Contributed equally

Key words: prostate cancer, benign prostatic hyperplasia, long non-coding RNA NCK1 antisense RNA 1, transforming growth factor- $\beta 1$ deprivation (5). Therefore, novel therapeutic approaches are required. However, the molecular pathogenesis underlying $\mathrm{PC}$ remains unknown, which limits the identification of novel therapeutic targets.

Long non-coding (lnc)RNAs (>200 nucleotides in length), which are transcribed by RNA polymerase II, are RNA transcripts that lack open reading frames, and thus encode no proteins (6). Previous studies have revealed that the major role of lncRNAs in diverse biological processes is the regulation of gene expression $(7,8)$. In cancer biology, lncRNAs regulate the expression of oncogenes or tumor suppressors to promote the inhibition of tumor development (9). Thus, certain key cancer-associated lncRNAs are considered promising targets for cancer therapy (10). Therefore, characterization of lncRNAs functions is required. NCK1 antisense RNA 1 (NCK1-AS1) has been characterized as an oncogenic lncRNA in cervical cancer (11). The present study was performed with the aim of investigating the role of NCK1-AS1 in PC.

\section{Materials and methods}

Research subjects. The research subjects of the present study

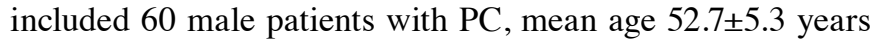
(range, 44-64 years); 58 male patients with $\mathrm{BPH}$, mean age 53.1 \pm 4.7 years (range, 43-65 years); and 60 healthy males, mean age $54.3 \pm 5.6$ years (range, $44-65$ years). All participants were diagnosed at The First Affiliated Hospital of Soochow University (Suzhou, China) between December 2015 and December 2018. The inclusion criteria of the patients were as follows: i) New cases diagnosed by histopathological examinations (blinded pathologists); ii) patients had received no form of therapy prior to admission; iii) patients had American Joint Committee on Cancer (AJCC) (12) stage I ( $=24)$ or stage II $(n=36)$. The exclusion criteria of the patients were as follows: i) Any other clinical disorders were observed, such as metabolic diseases and inflammatory diseases; ii) patients had received a form of therapy within 3 months prior to admission; iii) patients had a previous history of malignancies; iv) patients had a family history of malignancies. Based on the AJCC staging system, the 60 patients with PC included 8, 12, 19 and 21 cases at clinical stage I, II, III and IV, respectively. According to the Gleason grade (13), there were 6, 8, 12, 19 and 15 cases at grades I, II, III, IV and V, respectively. All 
participants had the principle experiment explained to them and written informed consent was provided by all patients and healthy males. The present study was approved by the Ethics Committee of The First Affiliated Hospital of Soochow University.

Plasma and cells. Prior to the initiation of any therapies, fasting blood $(5 \mathrm{ml})$ was extracted from the basilic vein of all patients with PC $(n=60)$, patients with BPH $(n=58)$ and healthy males $(n=60)$. Blood was transferred to EDTA-treated tubes and centrifuged for $15 \mathrm{~min}$ at $1,250 \mathrm{x}$ g at room temperature to separate serum.

The present study included two human PC cell lines, DU145 and 22Rv1 [American Type Culture Collection (ATCC)], and a normal prostate cell line, RWPE-1 (ATCC). Cells were cultured in Eagle's minimum essential medium [10\% fetal bovine serum (FBS; ATCC)] at $37^{\circ} \mathrm{C}$ and $5 \% \mathrm{CO}_{2}$. Cells were collected at $\sim 80 \%$ confluence for subsequent experimentation.

Reverse transcription-quantitative PCR (RT-qPCR). Plasma $(0.15 \mathrm{ml})$ or $10^{5}$ DU145, 22Rv1 and RWPE-1 cells were mixed with $1 \mathrm{ml} \mathrm{Ribozol}{ }^{\mathrm{TM}}$ RNA Extraction Reagent (Krackeler Scientific, Inc.) to extract total RNA. AMV Reverse Transcriptase (Sigma-Aldrich; Merck KGaA) and SYBR Green Master Mix (Bio-Rad Laboratories, Inc.) were used to perform the RT (at the following conditions: $20 \mathrm{~min}$ at $50^{\circ} \mathrm{C}$ and $10 \mathrm{~min}$ at $80^{\circ} \mathrm{C}$ ) or preparing qPCR mixtures with $18 \mathrm{~S}$ ribosomal (r)RNA or GAPDH as endogenous control to analyze the expression of NCK1-AS1 or TGF- $\beta 1$ mRNA, respectively. Sequences of primers were: NCK1-AS1 forward, 5'-TTCCCATTTCTCCCAGGTC-3' and reverse, 5'-TGGTTA CTTTGAGCCTGCC-3'; GAPDH forward, 5'-GGAGCGAGA TCCCTCCAAAA-3' and reverse, 5'-GGCTGTTGTCATACT TCTCATG-3'; TGF- $\beta 1$ forward, 5'-GGAGAGCCCTGGATA CCA AC-3' and reverse, 5'-CAACCCAGGTCCTTCCTA AA-3'; and 18S rRNA forward, 5'-CTACCACATCCAAGG AAGC-3' and reverse, 5'-TTTTCGTCACTACCTCCCCG-3'. The thermocycling conditions were as follows: Initial denaturation at $95^{\circ} \mathrm{C}$ for $1 \mathrm{~min}, 40$ cycles of $95^{\circ} \mathrm{C}$ for $10 \mathrm{sec}$ and $55^{\circ} \mathrm{C}$ for $40 \mathrm{sec}$. All experiments were repeated in triplicate and quantified using the $2^{-\Delta \Delta C q}$ method (14). The sample with the highest ${ }^{\Delta \mathrm{C} q}$ values was set to ' 1 ', and all other samples were normalized to this sample.

ELISA. TGF- $\beta 1$ in plasma was detected via ELISA using Human TGF- $\beta 1$ Quantikine ELISA kit (cat. no. DB100B; R\&D Systems, Inc.). Levels of TGF- $\beta 1$ were expressed as $\mathrm{ng} / \mathrm{ml}$.

Cell transient transfections. NCK1-AS1 and TGF- $\beta 1$ expression vectors were constructed by Sangon Biotech Co., Ltd. using a pcDNA3 vector. DU145 and 22Rv1 cells were collected when they had reached $70-90 \%$ confluence. Lipofectamine ${ }^{\circledR}$ 2000 reagent (Thermo Fisher Scientific, Inc.) was used transfect $10 \mathrm{nM}$ NCK1-AS1 or TGF- $\beta 1$ expression vector, or $10 \mathrm{nM}$ empty vector (negative control group; NC) into $10^{5}$ DU145 or $22 \mathrm{Rv} 1$ cells. This experiment also included cells that had not undergone transfection to serve as control cells (Control group; C). All subsequent experiments were performed using cells collected at $24 \mathrm{~h}$ after transfection.

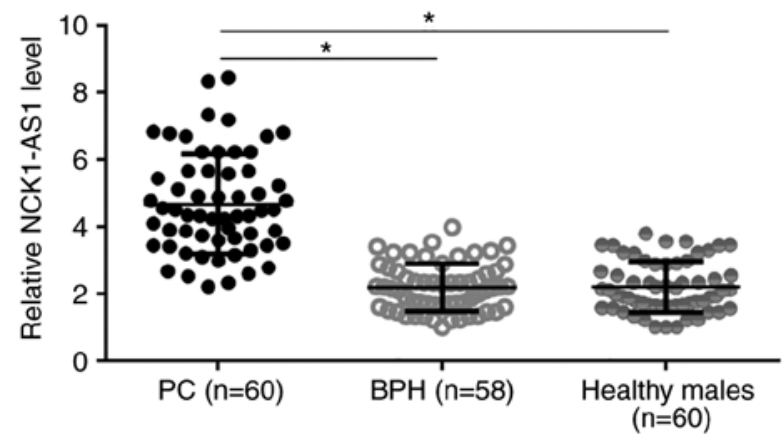

Figure 1. Plasma NCK1-AS1 was specifically upregulated in patients with PC. Plasma NCK1-AS1 was detected by performing reverse transcription-quantitative PCR, and expression data were analyzed with one-way analysis of variance and Tukey tests. Plasma levels of NCK1-AS1 were significantly higher in PC groups compared with in the other two groups. However, no significant differences were observed between patients with BPH and healthy males. ${ }^{*} \mathrm{P}<0.05$ vs. PC group. NCK1-AS1, NCK1 antisense RNA 1; PC, prostate cancer, $\mathrm{BPH}$, benign prostatic hyperplasia.

Measurement of cell migration and invasion abilities. At $24 \mathrm{~h}$ after transfection, DU145 and 22Rv1 cells were collected and $3 \times 10^{4}$ cells were mixed with $1 \mathrm{ml}$ Eagle's Minimum Essential Medium containing 1\% FBS to prepare single cell suspensions. In cases of TGF- $\beta$ inhibitor treatment, SB431542 (10 nM; SB; Sigma-Aldrich; Merck KGaA) was added into the cell suspensions. Matrigel (cat. no. 356234; EMD Millipore) was used to coat the upper Transwell chamber membrane, and $0.1 \mathrm{ml}$ cell suspension was added. The lower chamber was filled with the aforementioned medium containing $20 \%$ FBS. Cells were incubated at $37^{\circ} \mathrm{C}$ with $5 \% \mathrm{CO}_{2}$ for $24 \mathrm{~h}$, followed by staining of the lower face of the membranes with $1 \%$ crystal violet (Sigma-Aldrich; Merck KGaA) for 20 min at room temperature. The stained membranes were observed under a light microscope to count the cells.

Western blotting. At $24 \mathrm{~h}$ after transfections, DU145 and 22Rv1 cells were collected, and $2 \times 10^{5}$ cells were mixed with $1 \mathrm{ml}$ RIPA solution (Thermo Fisher Scientific, Inc.) for total protein extraction. Following protein denaturation, the proteins were separated via SDS-PAGE (10\% gel; $30 \mu \mathrm{g}$ per lane) and then transferred to PVDF membranes. Following blocking in 5\% non-fat milk ( $2 \mathrm{~h}$ at room temperature), TGF- $\beta 1$ (1:1,200; cat. no. ab92486) and GAPDH (1:1,200; cat. no. ab9485) rabbit polyclonal primary antibodies (both from Abcam) were incubated with the membranes at $4^{\circ} \mathrm{C}$ overnight. After that, IgG-horseradish peroxidase-conjugated goat anti-rabbit secondary antibody (1:1,000; cat. no. MBS435036; MyBioSource, Inc.) was incubated with the membranes for $2 \mathrm{~h}$ at room temperature. Finally, Pierce ECL Western Blotting Substrate (Pierce; Thermo Fisher Scientific, Inc.) was used to develop signals and Image J software (version 1.46; National Institutes of Health) was used to analyze the data.

Statistical analysis. All data are presented as the mean \pm standard deviation, which were calculated using data from 3 biological replicates of each experiment. Differences among 3 groups of participants or different groups of cells were analyzed using one-way analysis of variance (ANOVA) followed by Tukey tests. Correlations were analyzed via linear 

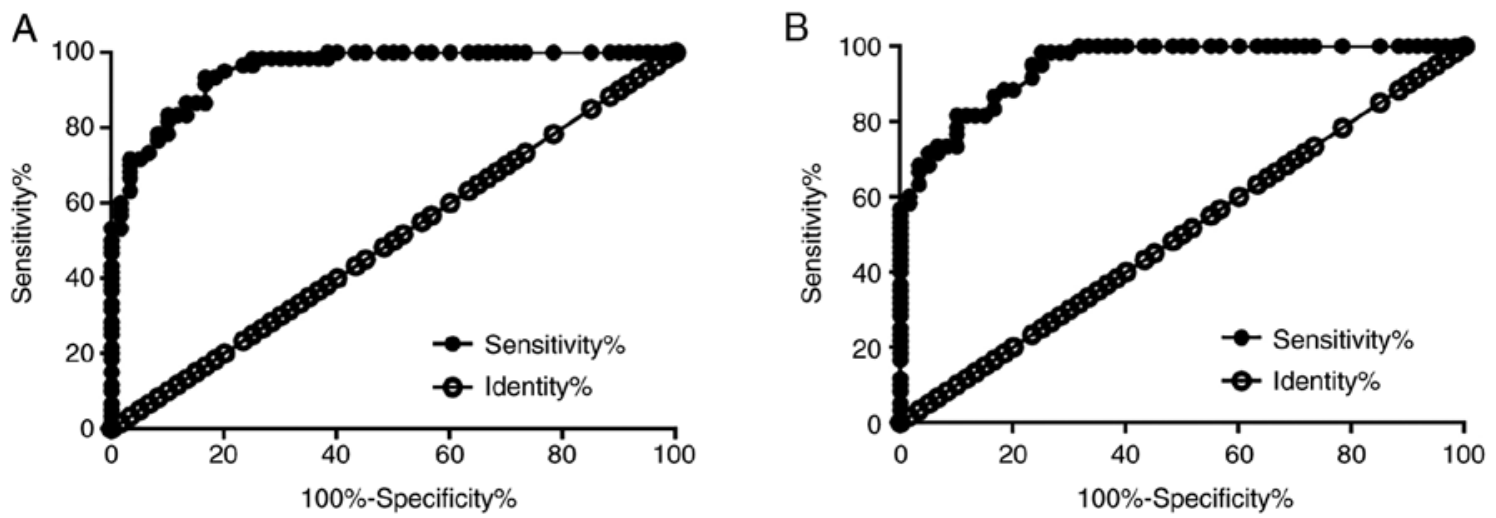

Figure 2. Upregulation of NCK1-AS1 distinguishes patients with PC from patients with BPH and healthy controls. Receiver operator characteristic curve analysis was performed to evaluate the diagnostic value of plasma NCK1-AS1 for PC. It was observed that upregulation of NCK1-AS1 distinguished patients with PC from (A) patients with BPH and (B) healthy males. NCK1-AS1, NCK1 antisense RNA 1; PC, prostate cancer, BPH, benign prostatic hyperplasia.

regression. A receiver operating characteristic (ROC) curve was used to analyze the diagnostic values. $\mathrm{P}<0.05$ was considered to indicate a statistically significant difference.

\section{Results}

Plasma NCK1-AS1 is specifically upregulated in patients with $P C$. Plasma NCK1-AS1 in patients with $\mathrm{PC}(\mathrm{n}=60)$, patients with $\mathrm{BPH}(\mathrm{n}=58)$ and healthy males $(\mathrm{n}=60)$ was detected by performing RT-qPCR, and the expression data were analyzed by performing one-way ANOVA and Tukey tests. It was observed that the plasma levels of NCK1-AS1 were significantly higher in the $\mathrm{PC}$ group than in the other two groups $(\mathrm{P}<0.05$; Fig. 1). However, no significant differences were observed between patients with BPH and healthy males (Fig. 1). It is also worth noting that the expression level of NCK1-AS1 was also significantly higher in DU145 (2.7-fold) and 22Rv1 (3.3-fold) cells than in RWPE-1 cells ( $\mathrm{P}<0.05$; Fig. S1). Furthermore, a slight increase in NCK1-AS1 levels alongside the increase of Gleason score (Fig. S2A) and clinical stages (Fig. S2B) was observed, but these increases were not significant.

Upregulation of NCK1-AS1 distinguishes patients with PC from patients with $\mathrm{BPH}$ and healthy males. The ROC curve analysis was performed to evaluate the diagnostic value of plasma NCK1-AS1 for PC. Patients with PC were used as true positive cases. For patients with BPH as true negative cases, the area under the curve (AUC) was 0.95, with a standard error of 0.017 and $95 \%$ confidence interval of 0.92-0.99 (Fig. 2A). With healthy males as true negative cases, area AUC was 0.95, with a standard error of 0.018 and $95 \%$ confidence interval of $0.92-0.98$ (Fig. 2B). The diagnostic value of TGF- $\beta 1$ for PC was analyzed by ROC, and the AUCs were 0.96 (standard error, $0.017 ; 95 \%$ confidence interval, 0.92-0.99) and 0.93 (standard error, 0.019; 95\% confidence interval, 0.91-0.97) in patients with BPH (Fig. S3A) and healthy controls (Fig. S3B), respectively, as true negative cases.

TGF- $\beta 1$ is positively correlated with NCK1-AS1 in the plasma of patients with $P C$. TGF- $\beta 1$ in the plasma of patients with PC was detected via ELISA. The correlation between TGF- $\beta 1$ and NCK1-AS1 in the plasma of patients with PC was analyzed with linear regression. As presented in Fig. 3, TGF- $\beta 1$ and

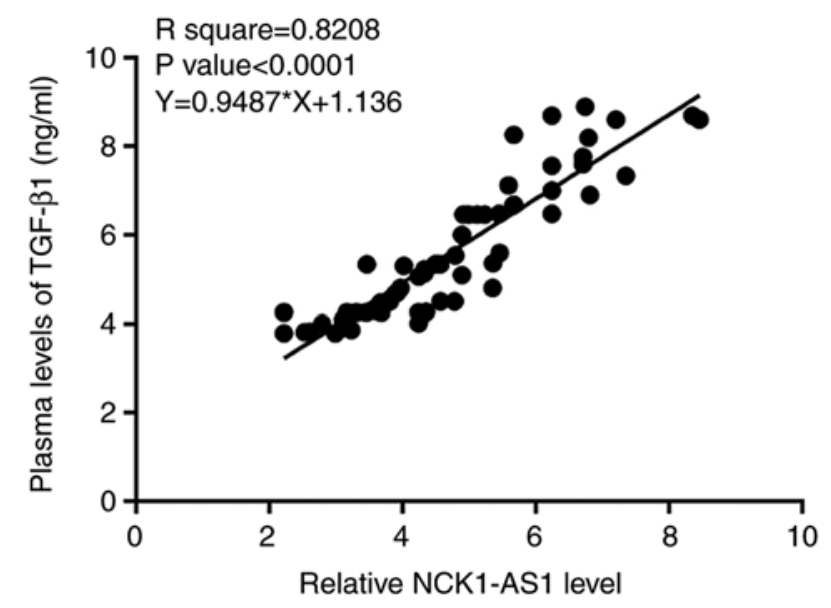

Figure 3 . TGF- $\beta 1$ was positively correlated with NCK1-AS1 in the plasma of patients with PC. Linear regression analysis revealed that plasma TGF- $\beta 1$ and NCK1-AS1 were positively and significantly correlated in patients with PC. TGF- $\beta 1$, transforming growth factor $\beta 1$; NCK1-AS1, NCK1 antisense RNA 1; PC, prostate cancer.

NCK1-AS1 were positively and significantly correlated $\left(r^{2}=0.8208 ; \mathrm{P}<0.0001\right)$.

NCK1-AS1 is an upstream positive regulator of TGF- $\beta 1$. NCK1-AS1 and TGF- $\beta 1$ expression vectors were transfected into DU145 and 22Rv1 cells. Compared with the C and NC control groups, the expression levels of NCK1-AS1 and TGF- $\beta 1$ were significantly increased at $24 \mathrm{~h}$ after transfection of NCK1-AS1 and TGF- $\beta 1$ expression vectors $(\mathrm{P}<0.05$; Fig. 4A). Furthermore, overexpression of NCK1-AS1 led to significantly upregulated TGF- $\beta 1$ at both the mRNA and protein levels $(\mathrm{P}<0.05$; Fig. $4 \mathrm{~B})$, while TGF- $\beta 1$ overexpression failed to significantly affect NCK1-AS1 in PC cells (Fig. 4C).

NCK1-AS1 regulated PC cell migration and invasion through $T G F-\beta 1$. NCK1-AS1 and TGF- $\beta 1$ overexpression resulted in increased invasion (Fig. 5A) and migration (Fig. 5B) rates of DU145 and 22Rv1 cells (all $\mathrm{P}<0.05$ ). Treatment with TGF- $\beta$ inhibitor SB431542 (10 nM; SB; Sigma-Aldrich; Merck KGaA) for $24 \mathrm{~h}$ played an opposite role and attenuated the effects of NCK1-AS1 overexpression ( $\mathrm{P}<0.05$; Fig. 5). 


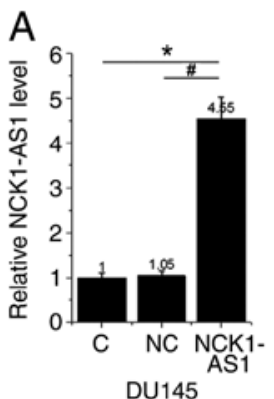

DU145
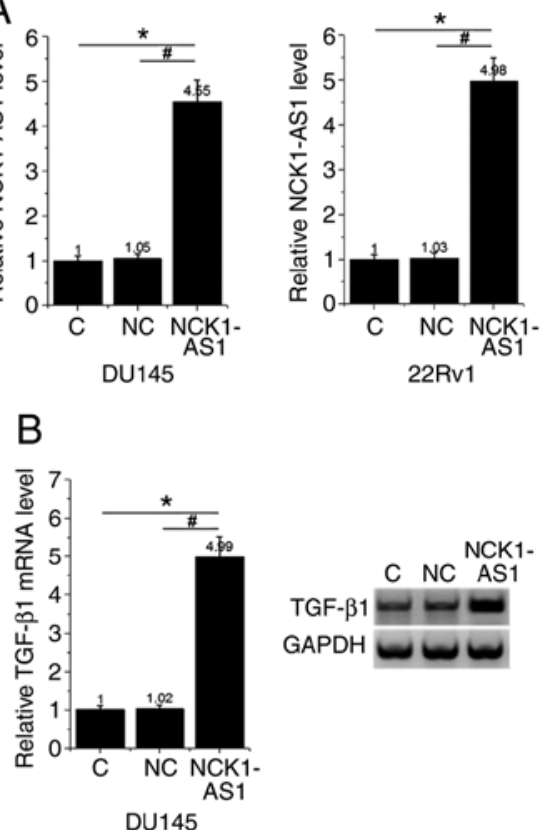
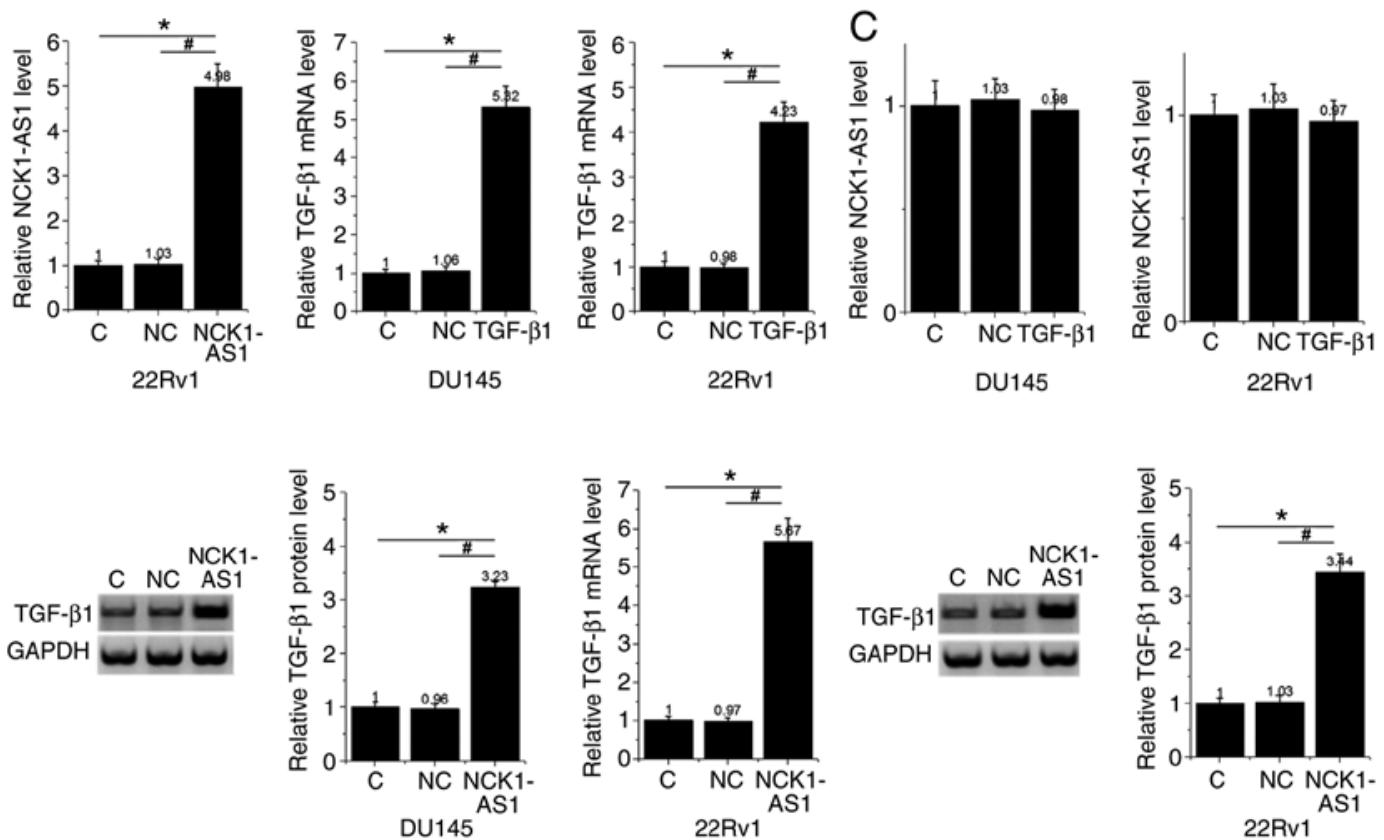

Figure 4. NCK1-AS1 is an upstream positive regulator of TGF- $\beta 1$. NCK1-AS1 and TGF- $\beta 1$ expression vectors were transfected into DU145 and 22 Rv1 cells, and (A) overexpression of NCK1-AS1 and TGF- $\beta 1$ was confirmed at $24 \mathrm{~h}$ after transfection. (B) Overexpression of NCK1-AS1 led to significantly upregulated TGF- $\beta 1$ at both mRNA and protein levels, while (C) TGF- $\beta 1$ overexpression failed to significantly affect NCK1-AS1 in PC cells. ${ }^{*} \mathrm{P}<0.05$ vs. C group; ${ }^{~} \mathrm{P}<0.05$ vs. NC group. NCK1-AS1, NCK1 antisense RNA 1; TGF- $\beta 1$, transforming growth factor $\beta 1$; C, control; NC, negative control.
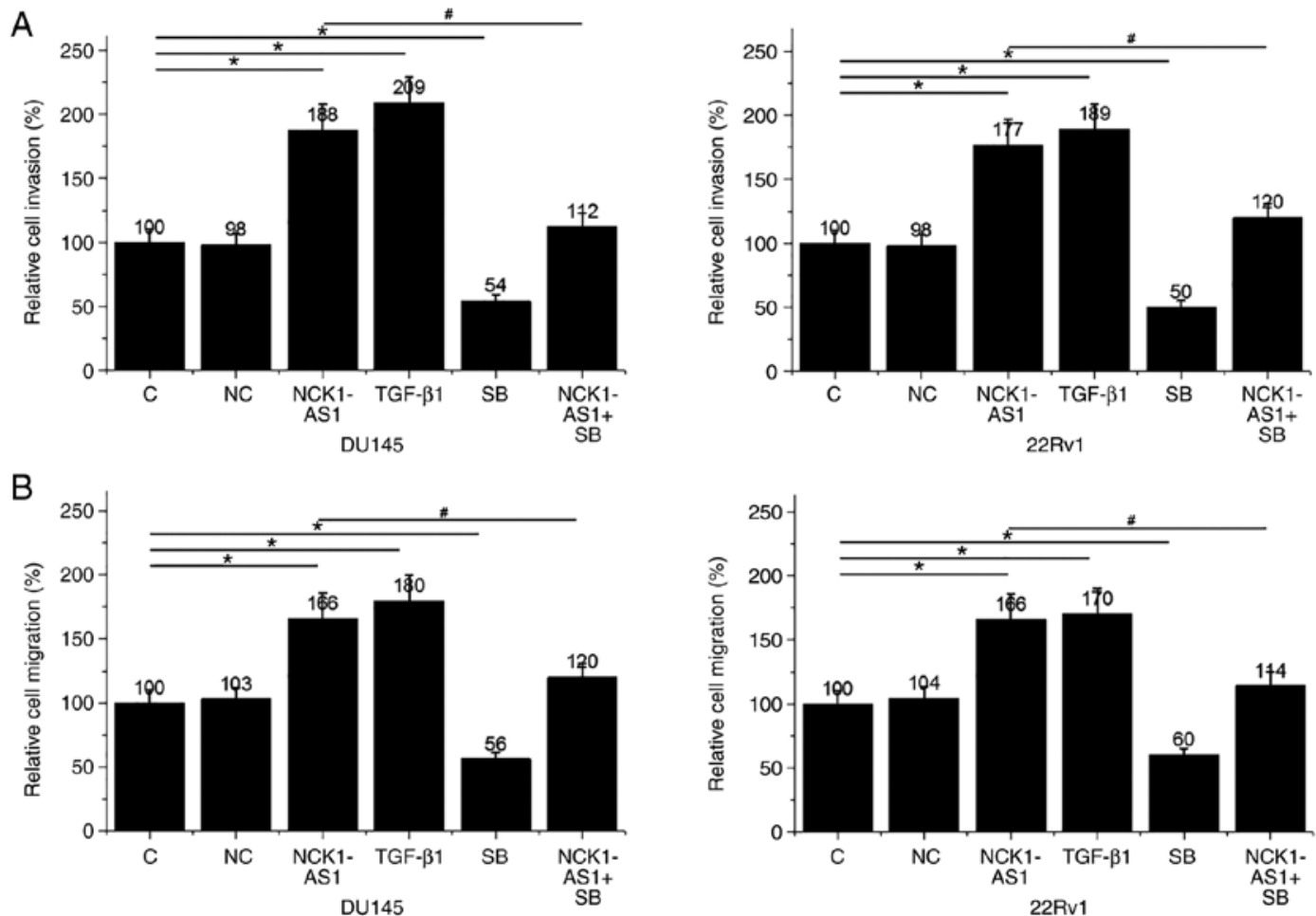

Figure 5. NCK1-AS1 regulated PC cell migration and invasion through TGF- $\beta 1$. The data from the Transwell migration and invasion analysis revealed that NCK1-AS1 and TGF- $\beta 1$ overexpression resulted in (A) increased invasion and (B) migration rates of DU145 and 22 Rv1 cells. TGF- $\beta$ inhibitor played an opposite role and attenuated the effects of NCK1-AS1 overexpression. ${ }^{*} \mathrm{P}<0.05$ vs. C group; ${ }^{*} \mathrm{P}<0.05$ vs. NCK1-AS1 group. NCK1-AS1, NCK1 antisense RNA 1; $\mathrm{PC}$, prostate cancer; TGF- $\beta 1$, transforming growth factor $\beta 1$; C, control; NC, negative control; SB, SB431542.

\section{Discussion}

The expression pattern, function and clinical potential of NCK1-AS1 for PC were systematically investigated in the present study. It was revealed that NCK1-AS1 was upregulated in $\mathrm{PC}$ and can be used to effectively distinguish PC from BPH and healthy controls. In addition, NCK1-AS1 may upregulate TGF- $\beta 1$ to promote PC cell migration and invasion. 
In the clinical practice, $\mathrm{PC}$ and $\mathrm{BPH}$ share similar imaging characteristics. Previous studies have developed multiple approaches to distinguish PC from $\mathrm{BPH}$, such as genetic and epigenetic markers (15) and blood-based multiple marker detection (16). However, these approaches are limited by the complicated operations and insufficient accuracy $(15,16)$. Due to the non-invasive nature, blood-circulating biomarkers, such as IncRNAs, have indicated promising potential in the prediction of disease (17). In the present study it was observed that NCK1-AS1 was upregulated in the plasma of patients with $\mathrm{PC}$, and upregulation of NCK1-AS1 distinguished patients with early stage (AJCC stage I and II) PC from patients with BPH and healthy males. Therefore, NCK1-AS1 may be used to assist with the early diagnosis of PC. Currently, biopsy is considered the best option for clinical diagnosis; however, biopsies are not practical in certain cases. Plasma markers are less or non-invasive. Therefore, plasma NCK1-AS1 may be popularized in clinical practices.

The TGF- $\beta$ pathway is involved in the multiple aspects of cancer development (18). Inhibition of TGF- $\beta$ signaling is a promising target for inhibiting cancer metastasis (19). In the present study, increased invasion and migration rate of PC cells was observed following TGF- $\beta$ overexpression, which confirmed the enhancing effects of TGF- $\beta$ on cancer metastasis. LncRNAs may regulate TGF- $\beta$ to participate in cancer biology (20). In the present study it was revealed that NCK1-AS1 can upregulate TGF- $\beta 1$ in PC cells, and the upregulation of TGF- $\beta 1$ by NCK1-AS1 is involved in the regulation of PC cell migration and invasion. However, the molecular mechanism underlying this interaction remains unclear. It is known that CDKs can interact with TGF- $\beta$ (21), while NCK1-AS1 regulates CDK1 in the regulation of cell cycle progression (22). Therefore, CDK1 may mediate the interaction between NCK1-AS1 and TGF- $\beta 1$. In addition, future studies will focus on the interactions between NCK1-AS1 and NCK1, which also have oncogenic functions (23).

Notably, NCK1-AS1 failed to affect PC cell proliferation, while a recent study reported that NCK1-AS1 can regulate cell cycle progression (22). This is potentially due to the specific cell lines used in the present study. Prostate specific antigen (PSA) has been widely used to distinguish PC and BPH, the levels of which also increase in patients with BPH (24). In the present study, significant differences in NCK1-AS1 levels between patients with BPH and healthy controls were observed, indicating that NCK1-AS1 possesses a higher accuracy. However, the present study failed to analyze PSA, as PSA levels were not available for all patients.

In conclusion, NCK1-AS1 was upregulated in PC and had screening potential. NCK1-AS1 may upregulate TGF- $\beta 1$ to promote $\mathrm{PC}$ cell migration and invasion.

\section{Acknowledgements}

Not applicable.

\section{Funding}

No funding was received.

\section{Availability of data and materials}

The datasets used and/or analyzed during the present study are available from the corresponding author upon reasonable request.

\section{Authors' contributions}

ZG and YS designed the experiments, analyzed the data and wrote the manuscript. JM, FL, XZ, GL and HA performed the experiments and clinical research. JP performed the research design and managed the project. All authors read and approved the final manuscript.

\section{Ethics approval and consent to participate}

Ethical approval was obtained from the Ethics Committee of the First Affiliated Hospital of Soochow University. All participants provided written informed consent.

\section{Patient consent for publication}

Not applicable.

\section{Competing interests}

The authors declare that they have no competing interests.

\section{References}

1. Bray F, Ferlay J, Soerjomataram I, Siegel RL, Torre LA and Jemal A: Global cancer statistics 2018: GLOBOCAN estimates of incidence and mortality worldwide for 36 cancers in 185 countries. CA Cancer J Clin 68: 394-424, 2018.

2. Gundem G, Van Loo P, Kremeyer B, Alexandrov LB, Tubio JMC, Papaemmanuil E, Brewer DS, Kallio HML, Högnäs G, Annala M, et al: The evolutionary history of lethal metastatic prostate cancer. Nature 520: 353-357, 2015.

3. Schweizer MT, Wang H, Luber B, Nadal R, Spitz A, Rosen DM, Cao H, Antonarakis ES, Eisenberger MA, Carducci MA, et al: Bipolar androgen therapy for men with androgen ablation naive prostate cancer: Results from the phase II BATMAN study. Prostate 76: 1218-1226, 2016.

4. Morgans AK, Chen YH, Sweeney CJ, Jarrard DF, Plimack ER, Gartrell BA, Carducci MA, Hussain M, Garcia JA, Cella D, et al: Quality of life during treatment with chemohormonal therapy: Analysis of E3805 chemohormonal androgen ablation randomized trial in prostate cancer. J Clin Oncol 36: 1088-1095, 2018.

5. Sun S, Sprenger CC, Vessella RL, Haugk K, Soriano K, Mostaghel EA, Page ST, Coleman IM, Nguyen HM, Sun H, et al: Castration resistance in human prostate cancer is conferred by a frequently occurring androgen receptor splice variant. J Clin Invest 120: 2715-2730, 2010.

6. Mercer TR, Dinger ME and Mattick JS: Long non-coding RNAs: Insights into functions. Nat Rev Genet 10: 155-159, 2009.

7. Engreitz JM, Ollikainen N and Guttman M: Long non-coding RNAs: Spatial amplifiers that control nuclear structure and gene expression. Nat Rev Mol Cell Biol 17: 756-770, 2016.

8. Dykes IM and Emanueli C: Transcriptional and post-transcriptional gene regulation by long non-coding RNA. Genomics Proteomics Bioinformatics 15: 177-186, 2017.

9. Gutschner T and Diederichs S: The hallmarks of cancer: A long non-coding RNA point of view. RNA Biol 9: 703-719, 2012

10. Spizzo R, Almeida MI, Colombatti A and Calin GA: Long non-coding RNAs and cancer: A new frontier of translational research? Oncogene 31: 4577-4587, 2012.

11. Zhang WY, Liu YJ, He Y and Chen P: Suppression of long noncoding RNA NCK1-AS1 increases chemosensitivity to cisplatin in cervical cancer. J Cell Physiol 234: 4302-4313, 2019. 
12. Edge SB and Compton CC: The American joint committee on cancer: The 7th edition of the AJCC cancer staging manual and the future of TNM. Ann Surg Oncol 17: 1471-1474, 2010

13. Epstein JI, Egevad L, Amin MB, Delahunt B, Srigley JR, Humphrey PA and Grading Committee: The 2014 international society of urological pathology (ISUP) consensus conference on gleason grading of prostatic carcinoma: Definition of grading patterns and proposal for a new grading system. Am J Surg Pathol 40: 244-252, 2016.

14. Livak KJ and Schmittgen TD: Analysis of relative gene expression data using real-time quantitative PCR and the 2(-Delta Delta C(T)) method. Methods 25: 402-408, 2001.

15. Sanchez BE, Aguayo A, Martinez B, Rodríguez F, Marmolejo M, Svyryd Y, Luna L, Muñoz LA, Jiménez MA, Sotomayor M, et al: Using genetic and epigenetic markers to improve differential diagnosis of prostate cancer and benign prostatic hyperplasia by noninvasive methods in Mexican patients. Clin Genitourin Cancer 16: e867-e877, 2018.

16. Leidinger P, Hart M, Backes C, Rheinheimer S, Keck B, Wullich B, Keller A and Meese E: Differential blood-based diagnosis between benign prostatic hyperplasia and prostate cancer: miRNA as source for biomarkers independent of PSA level, gleason score, or TNM status. Tumour Biol 37: 10177-10185, 2016.

17. Qi P, Zhou XY and Du X: Circulating long non-coding RNAs in cancer: Current status and future perspectives. Mol Cancer 15: 39, 2016.

18. Derynck R, Akhurst RJ and Balmain A: TGF-beta signaling in tumor suppression and cancer progression. Nat Genet 29: $117-129,2001$
19. Yingling JM, Blanchard KL and Sawyer JS: Development of TGF-beta signalling inhibitors for cancer therapy. Nat Rev Drug Discov 3: 1011-1022, 2004

20. Li Z, Dong M, Fan D, Hou P, Li H, Liu L, Lin C, Liu J, Su L, Wu L, et al: LncRNA ANCR down-regulation promotes TGF- $\beta$-induced EMT and metastasis in breast cancer. Oncotarget 8: 67329-67343, 2017.

21. Alarcón C, Zaromytidou AI, Xi Q, Gao S, Yu J, Fujisawa S, Barlas A, Miller AN, Manova-Todorova K, Macias MJ, et al: Nuclear CDKs drive Smad transcriptional activation and turnover in BMP and TGF-beta pathways. Cell 139: 757-769, 2009.

22. Li H, Jia Y, Cheng J, Liu G and Song F: LncRNA NCK1-AS1 promotes proliferation and induces cell cycle progression by crosstalk NCK1-AS1/miR-6857/CDK1 pathway. Cell Death Dis 9: 198, 2018.

23. Xia P, Huang M, Zhang Y, Xiong X, Yan M, Xiong X, Yu W and Song E: NCK1 promotes the angiogenesis of cervical squamous carcinoma via Rac1/PAK1/MMP2 signal pathway. Gynecol Oncol 152: 387-395, 2019

24. Benson MC, Whang IS, Pantuck A, Ring K, Kaplan SA, Olsson CA and Cooner WH: Prostate specific antigen density: A means of distinguishing benign prostatic hypertrophy and prostate cancer. J Urol 147: 815-816, 1992.

(i)(3) This work is licensed under a Creative Commons Attribution-NonCommercial-NoDerivatives 4.0 International (CC BY-NC-ND 4.0) License. 